\title{
A new simple algorithm for solution of optimization problems
}

\author{
Jeyhun Abbasov \\ Central Bank of Azerbaijan, Senior Economist, \\ Institute of Control Systems of ANAS, Doctorate, \\ Azerbaijan State University of Economics, International Graduate and \\ Doctorate Center, Lecturer, \\ Baku Engineering University, World Economy Department, Lecturer, \\ Baku, Azerbaijan \\ ceybunabbasoglu@gmail.com
}

\begin{abstract}
This paper is devoted to developing a new sample algorithm after the solution of optimization problems subject to a budget constraint in firms' production. In the calculation of the optimal composition of different items, there is one fundamental problem. In general, firm's behaviors are under a budget constraint and they always try to optimally allocate their resources among production factors. It is possible that there are some production factors like quality of labor force which influence firm's production after some period. In this case, when we want to solve optimization problems for these firms, we can encounter that the objective function (Revenue function, Production function or some other) of the optimization problem depends on the lags of the mentioned production factors. Therefore, the realization of the allocation of firm's resources among the production factors doesn't seem plausible (because some of them are on the lags). In this context, we have tried to prepare a simple algorithm for optimal allocation of firm's resources in the same period, using an optimal share which has been found for different lags of variables.
\end{abstract} $8330.2018 / 11-2 / 7$

Keywords: Optimization problem, production function, optimal allocation, lag effect in optimization

JEL Classification: C5, C6, E6

\section{INTRODUCTION}

Optimization methods have become very useful tools in both macroeconomic and microeconomic studies. For example, utility maximization (Lapan \& Brown, 1988 etc.), revenue maximization (Gershkov \& Moldovanu, 2009; Higgins, 1972 etc.), cost minimization (Ray, 2004; Wang et al., 2013 etc.), profit maximization (Kahana \& Nitzan, 1988; Chambers \& Echenique, 2009; Levin et al., 2004 etc.), production 
maximization (Just et al., 1983; Bernard et al., 2010 etc.) are optimization problems encountered in economics (Simon \& Blume, 1994; Chiang, 1984).

There are many samples for production, revenue, profit and cost function in microeconomic literatures. For example; Hu Z. H. examined the maximization problem of firm's production in the seller's market (Hu, 1998). Standard Cobb-Douglas production function is the objective function of this optimization problem while subject function has been constructed as the linear combination of labor and capital. Note that, the extension of Cobb-Douglas production function is applied in a lot of production practice. Another example which has been introduced by Grubbstrom R. W. He also used Cobb-Douglas production function $(\mathrm{Q}(\mathrm{X})$ ) with $n$ production factors but not standard version (Grubbstrom, 1995). In his work, sum of the coefficients of production function is equal to $\mathrm{z}$ (any value). Variation of parameter $\mathrm{z}$ leads to economic production analysis in three situations. $\mathrm{Q}(\mathrm{X})$ is called constant returns to scale, decreasing returns to scale and increasing returns to scale when $z=1,0<z<1$ and $z>1$, respectively.

This research aims to analyze the optimization problems related to firm's production. In literature, there are many research works devoted to this topic. Markusen developed the identical production functions for firms in the $X$ industry which are given by $X_{i}=X_{i}\left(L_{i x}, S_{i 1}, S_{i 2}, \ldots, S_{i n}\right)$, where $S_{j}$ is referred to as "specialized inputs". He investigated profit maximization problem on the basis of CES type production function (Markusen, 1990). Another interesting work is Griliches's research on the production function (Griliches, 1967). He introduced the quality of labor which was measured by an occupational mix variable as the production factor. His next research work (Griliches, 1968) also has been devoted to the mentioned issue (firm's production). In the latter work, Cobb-Douglas production function has been used and estimated by means of OLS. The quality of labor force (measured by "occupation mix" index) and the quality of capital stock are independent variables of this study jointly with some other variables. We can also find a useful feedback about firm's production function and related optimization problems in some additional research works (Hillestad, 1975; Liou et al., 2006; Chen et al., 2003; Pujowidianto et al., 2009; Amoranto \& Chun, 2011; and so on).

The question of our optimization problem is that firm's budget expenditures on some production factors, such as quality of labor force, rarely have a simultaneous impact on its production. For example, firms spend money in training of their employees, and the employees take time enough to acquire firmspecific skills (Naoki, 2011). Wagner note that "Usually, skill enhancement does not come to an end after passing the final exam in an apprenticeship program or a school..." (Wagner, 1997, pp. 421). He reported on the base of the IAB-Betriebspanel that share of employees who receive further training in small and medium sized firms less than share of the employees who receive further training in large firms. Note that, I encountered to mentioned evidence in some other research works (Abowd, Kramarz and Moreau, 1996; Fox and Smeets, 2011; Waldorf, 1973 etc.). So, these evidences let us to argue that, if a firm spends some money to improve its employees' skills in time $t$, then it is possible that these expenditures influence the firm's production after some period of time $(t+k)$. This statement requests that both objective function (production function) and subject function (cost or constraint function) are on the lags of expenditures for improving the quality of the labor force.

So this research work tried to offer a special algorithm which consists of three steps to analyze the distribution of firm's factors spending (say $b$ ) in any quarter (say k-th quarter) among production factors $\left(b_{k}\right.$ divided into $x_{k}, y_{k}$ (suppose that $x$ and $y$ are the production factors)) was optimal or not. In applying of these steps, three cases can be appear. 1) Maximum lag length greater than 3 (case 1) and 2) maximum lag length less than 3 (case 2) and 3) maximum lag length is equal to 3 (case 3). In Case 1, we can only analyze the distribution of the budget expenditures in past quarters. Actually, if we want to define optimal allocation of budget expenditures in Q1 of the next year we need value (limit) of the quarters after the next year (because maximum lag length greater than) which are unknown. In Case 2 and Case 3, we can both analyze 
the distribution of the budget expenditures in past quarters and define the optimal allocation at least for first quarter of the next year. Actually, if we want to define optimal allocation of budget expenditures in Q1 of the next year we need value (limit) of the quarters $\left(b_{t+1}, b_{t+2}, b_{t+3}\right)$ of the next year (because maximum lag length less than and eaual to 3 ) which are known. As above mentioned, the optimal allocation at least for first quarter of the next year can be defined. It means that we can suggest the optimal distribution of budget expenditures at least for first quarter of the next year in Case 2 and Case 3.

\section{METHODOLOGY AND RESULTS}

\subsection{Description of the problem}

We noted in the introduction that, the main purpose of this research is to determine a new simple algorithm after the solution of optimization problems in which there are some variables on the lags in objective and subject functions. Suppose that, firm's production depends on $n$ production factors. Let's denote these factors by $X_{i}(i=1,2, \ldots, \mathrm{n})$. Assume that, some of them currently have an impact while some of them have the impact with the lags on the firm's production. Let, the firm wants to maximize its production in the condition of budget constraint. Now suppose that this production process has been described by any production function $f$ and budget constraint has been described by constraint function $C$. Then we can write mathematical shape of this problem as follows (Simon and Blume, 1994; Chiang, 1984; Just et. al., 1983):

$$
\max _{X \in D} f_{t}\left(X_{i, t-p}\right)
$$

Subject to:

$$
C\left(X_{i, t-p}\right) \leq b_{t}
$$

Where, $i=1,2, \ldots, n$ and $t=1,2, \ldots, T . \mathrm{D}$ is a nonnegative subset of $\mathrm{R}, \quad X_{i, t-p}=$ $\left[X_{1, t-p_{1}}, X_{2, t-p_{2}}, \ldots, X_{n, t-p_{n}}\right]$ is a vector of production factors, $p=0,1,2, \ldots, P$ and $f: D \rightarrow R$ is an objective function or production function, $C: D \rightarrow R$ is a constraint function or cost function, and $b_{t}$ is a budget constraints in time $t$.

Note that (1)-(2) is constraint optimization problem on the $X$ (production factors) and it can be constructed as a linear and non-linear optimization problem. There are various ways of solution to such problems in the optimization course. Note that it doesn't matter us. Because this paper describes an algorithm after solution and we will assume that the solution of (1)-(2) optimization problem have already been found. Suppose that this solution is as follows:

$$
\boldsymbol{\varphi}=\left[\varphi_{i}\right]
$$

Where, $\varphi_{i}$ are optimal allocation of firm's resources $b_{t}$ (budget constraints) among $X_{i, t-p}$, respectively and $i=1,2, \ldots, n ; p=0,1,2, \ldots, P$.

There is a problem that the constraint condition (2) is on the lags of the variables because objective function (1) relies on the function of lags of these variables. Now suppose that,

$$
\boldsymbol{X}_{t}^{*}=\left[X_{t-p, i}^{*}\right]
$$


is an optimal solution of (1)-(2) optimization problem. Where, $i=1,2, \ldots, n ; p=0,1,2, \ldots, P ; t=1,2, \ldots$ ,$T$.

Let, subject function (2) is the linear budget constraint condition which is following:

$$
\sum_{i=1}^{n} X_{t-p, i}^{*} \leq b_{t}
$$

Then, we can define optimal shares of firm's budget among production factors as follows:

$$
\varphi=\left[\varphi_{i}=\frac{X_{t-p, i}^{*}}{b_{t}}\right]
$$

Where, $X_{t-p, i}^{*}$ are optimal value of production factors, $b_{t}$ is firm's budget constraints in time $t$ and $i=1,2$, $\ldots, n ; p=0,1,2, \ldots, P ; t=1,2, \ldots, T$.

Table 1

Firm's spending schema among production factors

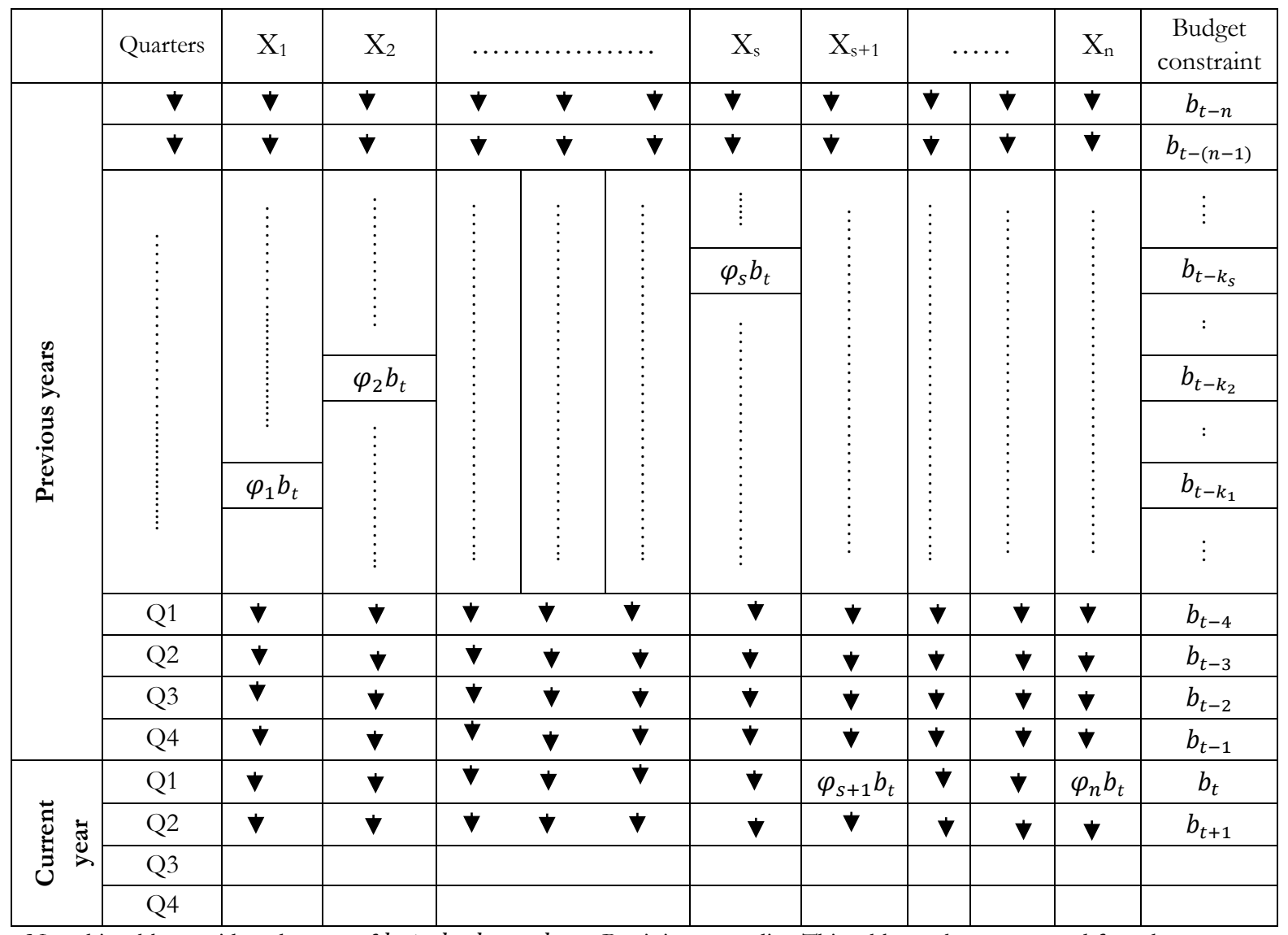

Note: this table considers the case of $k_{s} \geq k_{1}, k_{2}, \ldots, k_{s-1}$. But it is not verdict. This table can be constructed for other cases. For example, $k_{s-1} \geq k_{1}, k_{2}, \ldots, k_{s}$, and so on. Where, $k_{1}, k_{2}, \ldots, k_{s-1}, k_{s} \in[1, P]$.

Source: authors' own completion.

Now, assume that the firm has $n$ production factors and $s$ factors $(\mathrm{s}<\mathrm{n})$ from $n$ are on the lags. Then, we can write (5) and (6) as follows:

$$
X_{t-k_{1}, 1}^{*}+X_{t-k_{2}, 2}^{*}+\cdots+X_{t-k_{s}, s}^{*}+X_{t, s+1}^{*}+X_{t, s+2}^{*}+\cdots+X_{t, n}^{*} \leq b_{t}
$$




$$
\varphi=\left[\varphi_{1}=\frac{X_{t-k_{1}, 1}^{*}}{b_{t}}, \varphi_{2}=\frac{X_{t-k_{2}, 2}^{*}}{b_{t}}, \ldots, \varphi_{s}=\frac{X_{t-k_{s}, s}^{*}}{b_{t}}, \varphi_{s+1}=\frac{X_{t, s+1}^{*}}{b_{t}}, \varphi_{s+2}=\frac{X_{t, s+1}^{*}}{b_{t}}, \ldots, \varphi_{n}=\frac{X_{t, n}^{*}}{b_{t}}\right]
$$

Where, $k_{z} \in[1, P](z=1,2, \ldots, s)$ are lags.

In Table 1, we have tried to describe this situation.

Now suppose that $b_{t}$ is the limit in first quarter of current year in Table 1. For solution (7) and (8), firm must spend $\varphi_{1} b_{t}$ share of value $b_{t}$ for $X_{1}$, must spend $\varphi_{2} b_{t}$ share of value $b_{t}$ for $X_{2}, \ldots \ldots$.. and must spend $\varphi_{s} b_{t}$ shares of value $b_{t}$ for $\mathrm{X}_{s}, \mathrm{k}_{1}, \mathrm{k}_{2}, \ldots, \mathrm{k}_{\mathrm{s}}$ lags before, respectively for maximizing its production in Q1 of current year. In same way, $\varphi_{1} b_{t-1}, \varphi_{2} b_{t-1}, \ldots \ldots \ldots$ and $\varphi_{s} b_{t-1}$ shares of value $b_{t-1}$ must be spent for $\mathrm{X}_{1}, \mathrm{k}_{1}$ lags before, for $\mathrm{X}_{2}, \mathrm{k}_{2}$ lags before, ......... and for $\mathrm{X}_{\mathrm{s}}, \mathrm{k}_{\mathrm{s}}$ lags before, respectively for maximizing its production in Q4 of previous year (see Table 1). But it seems impossible. This phenomena causes the problem to use the results of the solutions of (1)-(2) optimization problem. If we can answer below question, then we achieve success in solution of this problem.

Question: Has $b_{t-k_{z}}$ (constraint (value) in any quarter) been optimal distributed among $X_{t-k_{z}, i}(i=$ $\left.1,2, \ldots, n ; k_{z} \in[1, P], z=1,2, \ldots, s\right)$ on base of the optimal solution $\boldsymbol{X}_{t}^{*}=\left[X_{t-p, i}^{*}\right](p=0,1,2, \ldots, P)$ of the (1)-(2) optimization problem under condition of $k_{s} \geq k_{1}, k_{2}, \ldots, k_{s-1}$

$\left(\right.$ or $k_{1} \geq k_{2}, k_{3}, \ldots, k_{s}, \ldots \ldots$, or $\left.k_{s-1} \geq k_{1}, k_{2}, \ldots, k_{s}\right)$ ?

\subsection{A Solution of the problem and result}

First of all, assume that there are three properties;

[A] The value of firm's budget expenditures for the next year is known in advance (in the current year), [B] Expenditures in the current quarter are proportionate to the expenditures in the previous quarter. Mathematically, it can be written as follows:

$$
b_{t}=\omega_{t} b_{t-1}, b_{t-1}=\omega_{t-1} b_{t-2}, b_{t-2}=\omega_{t-2} b_{t-3}, \ldots \ldots \ldots, b_{t-n+1}=\omega_{t-n+1} b_{t-n}
$$

[D] Let, the firm has $n$ production factors and $s$ factors from $n$ are on the lags while remain factors have only currently impact on firm's production.

Suppose that, properties [A], [B] and [D] are available and suppose that $\boldsymbol{X}_{t}^{*}=\left[X_{t-p, i}^{*}\right]=\left[\varphi_{i}\right](i=1$, $2, \ldots, n ; p=0,1,2, \ldots, P ; t=1,2, \ldots, T)$ is the optimal solution of (1)-(2) optimization problem. Let, $\psi_{t-k_{z}}=\theta_{t-k_{z}} b_{t-k_{z}}\left(k_{z} \in[1, P], z=1,2, \ldots, s, \theta_{t-k_{z}}>0\right)$ and $k_{z} \geq k_{1}, k_{2}, \ldots, k_{s}$.

Now for simplicity, suppose that firm has only three production factors: $X_{1}, X_{2}$, and $X_{3}$. Assume that each factor influences firm's production with the lags and suppose that, each factor has only one stage lag effect ${ }^{1}$. Suppose that, the optimal solution is as following:

$$
\boldsymbol{X}_{t}^{*}=\left[X_{1, t-1}^{*}, X_{2, t-2}^{*}, X_{3, t-3}^{*}\right]=\left[\varphi_{1}, \varphi_{2}, \varphi_{3}\right]
$$

Now let's accept that $k_{1}=1, k_{2}=2, k_{3}=3$ and use Table 1 for only two years: current and next. Then, on the base of optimal solution (10), to maximize, the firm must spend $\varphi_{1}$ share of value $b_{t}\left(\varphi_{1} b_{t}\right) 1$ lag before for $X_{1}, \varphi_{2}$ share of value $b_{t}\left(\varphi_{2} b_{t}\right) 2$ lag before for $X_{2}$ and $\varphi_{3}$ share of value $b_{t}\left(\varphi_{3} b_{t}\right) 3$ lag before

${ }^{1}$ If production depends on $X_{i, t-j}(i=1,2, \ldots \mathrm{n} ; \mathrm{j}=1,2, \ldots \mathrm{m})$ we can say "multiple stages lag effect". If production depends on $X_{i, t-1}(\mathrm{i}=1,2, \ldots, \mathrm{n})$ we can say "one stage lag effect" 
for $X_{3}$ (see Table 2). If we continue the process with the same pattern, analogously, $\varphi_{1}$ share of value $b_{t-1}$ $\left(\varphi_{1} b_{t-1}\right) 1$ lag before for $X_{1}, \varphi_{2}$ share of value $b_{t-1}\left(\varphi_{2} b_{t-1}\right) 2$ lag before for $X_{2}$ and $\varphi_{3}$ share of value $b_{t-1}\left(\varphi_{3} b_{t-1}\right) 3$ lag before for $X_{3}$ (see Table 2$)$ must be spent for maximizing of the influence of budget spending. We can see this process more clearly in the Table 2.

Table 2

Firm's spending schema among 3 production factors for only two years

\begin{tabular}{|c|c|c|c|c|c|}
\hline & Quarters & $\mathrm{X} 1$ & $\mathrm{X} 2$ & $\mathrm{X} 3$ & $\begin{array}{c}\text { Limits of } \\
\text { quarters }\end{array}$ \\
\hline \multirow{4}{*}{$\begin{array}{c}\text { Current } \\
\text { year }\end{array}$} & $\mathrm{Q} 1$ & $\varphi_{1} b_{t-3}$ & $\varphi_{2} b_{t-2}$ & $\varphi_{3} b_{t-1}$ & $b_{t-4}$ \\
\cline { 2 - 6 } & $\mathrm{Q} 2$ & $\varphi_{1} b_{t-2}$ & $\varphi_{2} b_{t-1}$ & $\varphi_{3} b_{t}$ & $b_{t-3}$ \\
\cline { 2 - 6 } & $\mathrm{Q} 3$ & $\varphi_{1} b_{t-1}$ & $\varphi_{2} b_{t}$ & $\boldsymbol{\nabla}$ & $b_{t-2}$ \\
\hline & $\mathrm{Q} 4$ & $\varphi_{1} b_{t}$ & $\boldsymbol{\nabla}$ & $\boldsymbol{\nabla}$ & $b_{t-1}$ \\
\hline \multirow{4}{*}{ Next year } & $\mathrm{Q} 1$ & $\boldsymbol{\nabla}$ & $\boldsymbol{\nabla}$ & $\boldsymbol{\nabla}$ & $b_{t}$ \\
\cline { 2 - 6 } & $\mathrm{Q} 2$ & $\boldsymbol{\nabla}$ & $\boldsymbol{\nabla}$ & $\boldsymbol{}$ & \\
\cline { 2 - 6 } & $\mathrm{Q} 3$ & $\boldsymbol{\nabla}$ & $\boldsymbol{\nabla}$ & $\boldsymbol{}$ & \\
\cline { 2 - 6 } & $\mathrm{Q} 4$ & & & & \\
\hline
\end{tabular}

Source: authors' own completion.

Now, let's begin with the Q2 of the current year. We can see that, $k_{3}=3$ and $k_{3}>k_{1}, k_{2}$ has been provided. The question is how we can share the value $b_{t-3}$ among $X_{1}, X_{2}$ and $X_{3}$ in Q2 of current year, so that spending can have maximum influence to firm's production? So, we can write the mentioned optimization principle in Table 2 as following:

$$
\varphi_{1} b_{t-2}+\varphi_{2} b_{t-1}+\varphi_{3} b_{t}=\theta_{t-3} b_{t-3}
$$

Let, $\psi_{t-3}=\theta_{t-3} b_{t-3}\left(\theta_{t-3}\right.$ is any positive number $)$

Now we can get a new optimal allocation of budget expenditures among $X_{1}, X_{2}$, and $X_{3}$ in $\mathrm{Q} 2$ of the current year as following:

$$
\left[\varphi_{1}{ }^{\prime}, \varphi_{2}{ }^{\prime}, \varphi_{3}{ }^{\prime}\right]=\left[\frac{\varphi_{1} b_{t-2}}{\psi_{t-3}}, \frac{\varphi_{2} b_{t-1}}{\psi_{t-3}}, \frac{\varphi_{3} b_{t}}{\psi_{t-3}}\right]
$$

Then, we can say that (12) is the optimal distribution of budget expenditures among $X_{1}, X_{2}$, and $X_{3}$ in $\mathrm{Q} 2$ of the current year. It means that this distribution can have the maximum influence on firm's production in the next quarters. But there is one important point in this statement: $b_{t-3}$ must be assigned by $\frac{1}{\theta_{t-3}} \psi_{t-3}$.

Now we can apply this statement to the general case. So, let's define the optimal distribution of budget limit for any time (period) among $X_{1}, X_{2}, \ldots, X_{n}$. For this, below simple algorithm can be used:

Step 1: The longest lag is defined. Suppose that, this lag is $k_{s}$ and the condition $k_{s} \geq k_{1}, k_{2}, \ldots, k_{s-1}$ is available.

Step 2: The budget constraint $\left(b_{t-k_{s}}\right)$ and distribution of this value among the production factors are reconstructed as following:

$$
\varphi_{1} b_{t-\left(k_{s}-k_{1}\right)}+\varphi_{2} b_{t-\left(k_{s}-k_{2}\right)}+\cdots+\varphi_{s} b_{t-\left(k_{s}-k_{s}\right)}+\varphi_{s+1} b_{t-\left(k_{s}-0\right)}+\cdots+\varphi_{n} b_{t-\left(k_{s}-0\right)}=\psi_{t-k_{s}}
$$


Step 3: The new optimal allocation of the budget among the production factors is calculated as following on the base of step 2

$$
\left[\varphi_{i}^{\prime}\right]=\left[\frac{\varphi_{1} b_{t-\left(k_{S}-k_{1}\right)}}{\psi_{t-k_{S}}}, \frac{\varphi_{2} b_{t-\left(k_{S}-k_{2}\right)}}{\psi_{t-k_{S}}}, \ldots, \frac{\varphi_{s} b_{t-\left(k_{S}-k_{S}\right)}}{\psi_{t-k_{S}}}, \frac{\varphi_{s+1} b_{t-k_{S}}}{\psi_{t-k_{S}}}, \frac{\varphi_{s+2} b_{t-k_{S}}}{\psi_{t-k_{S}}}, \ldots, \frac{\varphi_{n} b_{t-k_{S}}}{\psi_{t-k_{S}}}\right]
$$

Where, $\psi_{t-k_{s}}=\theta_{t-k_{s}} b_{t-k_{s}}\left(\theta_{t-k_{s}}\right.$ is any positive number $)$ and $\mathrm{s}=1,2, \ldots ., \mathrm{S} ; S \in n ; n$ is total number of firm's production factors

So we saw that, if properties $[\mathrm{A}],[\mathrm{B}]$ and $[\mathrm{D}]$ are available and $\boldsymbol{X}_{t}^{*}=\left[X_{t-p, i}^{*}\right]=\left[\varphi_{i}\right](i=1,2, \ldots, n ; p$ $=0,1,2, \ldots, P ; t=1,2, \ldots, T)$ is the optimal solution of (1)-(2) optimization problem. Then (14) can be used as optimal shares of firm's budget constraint $b_{t-k_{z}}$ among $X_{t-k_{z}}(i=1,2, \ldots, n)$ under terms of $k_{z} \geq$ $k_{1}, k_{2}, \ldots, k_{s}$ and $\psi_{t-k_{z}}=\theta_{t-k_{z}} b_{t-k_{z}}\left(k_{z} \in[1, P] ; z=1,2, \ldots, s ; \theta_{t-k_{z}}>0\right)$.

\section{DISCUSSION}

Note that (1)-(2) is constraint optimization problem on the $X$ (production factors) and it can be constructed as a linear and non-linear optimization problem. There are various ways of solution to such problems in the optimization course. Note that it doesn't matter us. Because this paper describes an algorithm after solution and we will assume that the solution of (1)-(2) optimization problem have already been found. In the solution process, we met three cases as the result of the proof.

Case 1: $k_{z}>3, k_{z} \geq k_{1}, k_{2}, \ldots, k_{s}\left(k_{z} \in[1, s] ; s \in n\right)$. In this case we can only analyze the distribution of the budget expenditures in past quarters. Actually, if we want to define optimal allocation of budget expenditures in Q1 of the next year we need value (limit) of the quarters after the next year (because $k_{Z}>3$ ) which are unknown.

Case 2: $k_{z}<3, k_{z} \geq k_{1}, k_{2}, \ldots, k_{s}\left(k_{z} \in[1, s] ; s \in n\right)$.

Case 3: $k_{z}=3, k_{z} \geq k_{1}, k_{2}, \ldots, k_{s}\left(k_{z} \in[1, s] ; s \in n\right)$.

In Case 2 and Case 3, we can both analyze the distribution of the budget expenditures in past quarters and define the optimal allocation at least for first quarter of the next year. Actually, if we want to define optimal allocation of budget expenditures in Q1 of the next year we need value (limit) of the quarters $\left(b_{t+1}, b_{t+2}, b_{t+3}\right)$ of the next year which are known on the base of property [A]. As above mentioned, the optimal allocation at least for first quarter of the next year can be defined. It means that we can suggest the optimal distribution of budget expenditures at least for first quarter of the next year in the case of $k_{z} \leq 3$.

\section{CONCLUSION}

This research concentrate on a problem which takes into consideration the distribution of firms' budget among production factors in the same period on the base of solution of optimization problem. More accurately, firms usually have some production factors like quality of labor force which may be influence to the firm's production after some period and therefore, the optimal solution have only theoretical meaning. In this context, the realization of the distribution of firm's budget among the production factors seems impossible. This research shows how we can use the optimal solution if constraint functions are on the lags of variables.

So, for the solution of this problem we use a simple algorithm which consists of three consistent steps. In realization of the steps, one of three cases is occured. 1) Maximum lag length greater than 3 (case 1), 2) maximum lag length less than 3 (case 2) and 3) maximum lag length is equal to 3 (case 3). In Case 1, we can only analyze the distribution of the budget expenditures in past quarters. Actually, if we want to define optimal allocation of budget expenditures in first quarter of the next year we need value (limit) of the 
quarters after the next year (because lag length greater than 3) which are unknown. In Case 2 and Case 3, we can both analyze the distribution of the budget expenditures in past quarters and define the optimal allocation at least for first quarter of the next year. Actually, if we want to define optimal allocation of budget expenditures in first quarter of the next year we need value (limit) of the quarters of the next year (because maximum lag length less than and eaual to 3) which are known. As above mentioned, the optimal allocation at least for first quarter of the next year can be defined. It means that we can suggest the optimal distribution of budget expenditures at least for first quarter of the next year in Case 2 .

\section{ACKNOWLEDGMENTS}

I would like to thank Mr. Elchin Gulaliyev who is an Economist at the Central Bank of Azerbaijan for editorial support.

\section{REFERENCES}

Abowd, J. M., Kramarz, F. \& Moreau, A. (1996). Product Quality and Worker Quality. Annales d'Économie et de Statistique, No. 41/42, 299-322. doi: http://www.jstor.org/stable/20066473

Amoranto G. \& Chun N. (2011). Quality Employment and Firm Performance Evidence from Indian Firm-Level Data. ADB Economics Working Paper Series No. 277. Asian Development Bank.

Bernard B. A., Redding J. S. \& Schott K. P. (2010). Multiple-Product Firms and Product Switching. The American Economic Review, 100(1), 70-97.

Chambers, C. P., \& Echenique, F. (2009). Profit maximization and supermodular technology. Economic Theory, 40(2), 173-183.

Chen C. H., Donohue K., Yücesan E., \& Lin J. (2003). Optimal computing budget allocation for Monte Carlo simulation with application to product design. Simulation Modelling Practice and Theory, 11, 57-74.

Chiang, A. C. (1984). Fundamental Methods of Mathematical Economics, third edition. Singapore, McGraw Hill.

Fox, J. T., \& Smeets, V. (2011). Does input quality drive measured differences in firm productivity?. International Economic Review, 52(4), 961-989.

Gershkov, A. \& Moldovanu, B. (2009). Dynamic Revenue Maximization with Heterogeneous Objects: A Mechanism Design Approach. American Economic Journal: Microeconomics, 1(2), 168-198.

Griliches, Z. (1967). Production Functions in Manufacturing: Some Preliminary Results in M. Brown, ed., The Theory and Empirical Analysis of Production, NBER. Studies in Income and Wealth, 3.

Griliches, Z. (1968). Production Functions in Manufacturing: Some Additional Results. Southern Economic Journal, 35(2), 151-156.

Grubbström, R. W. (1995). Modelling production opportunities—an historical overview. International Journal of Production Economics, 41(1-3), 1-14.

Higgins, G. (1972). An Algorithm for Revenue Maximization Subject to a Profit Constraint. Zeitschrift fuir die gesamte Staatswissenschaft / Journal of Institutional and Theoretical Economics, 128(1), 1-9.

Hillestad, R. J. (1975). Optimization problems subject to a budget constraint with economies of scale. Operations Research, 23(6), 1091-1098.

Hu, Z. H. (1998). Reliable optimal production control with Cobb-Douglas model. Reliable Computing, 4(1), 63-69.

Just, R. E., Zilberman, D., \& Hochman, E. (1983). Estimation of multicrop production functions. American Journal of Agricultural Economics, 65(4), 770-780.

Kahana, N., \& Nitzan, S. (1988). Production theory with profit-constrained revenue-maximization: The duality approach. Managerial and Decision Economics, 9(4), 269-273.

Kuhn, H. W. \& Tucker, AW (1951). Nonlinear programming. In Proceedings of 2nd Berkeley Symposium. Berkeley: University of California Press (pp. 481-492).

Lapan, H. E., \& Brown, D. M. (1988). Utility maximization, individual production, and market equilibrium. Southern Economic Journal, 55(2), 374-389. 
Levin, E. J., Ma, Y., \& Wright, R. E. (2004). Profit maximization in a multi-product firm with impatient customers. Journal of the Operational Research Society, 55(3), 211-218.

Liou, T., Chen, C., \& Chen, J. (2006). Optimal allocation of production resources for a multi-plant firm. International journal of information and management sciences, 17(4), 35-50.

Markusen, J. R. (1990). Micro-Foundations of External Economies. The Canadian Journal of Economics, 23(3), 495-508.

Naoki, S. (2011). Quality of Labor, Capital, and Productivity Growth in Japan: Effects of employee age, seniority, and capital vintage. RIETI Discussion Paper Series 11-E-036. Development Bank of Japan.

Pujowidianto, N. A., Lee, L. H., \& Chen, C. H. (2009). Optimal Computing Budget Allocation for constrained optimization. Proceedings of the 2009 Winter Simulation Conference, Institute of Electrical and Electronics Engineers, Inc.

Raimon, R. L., \& Stoikov, V. (1967). The quality of the labor force. ILR Review, 20(3), 391-413.

Ray, S. C. (2004). A Simple Statistical Test of Violation of the Weak Axiom of Cost Minimization. Indian Economic Review, 39(1), 111-121.

Simon, C. P., \& Blume, L. (1994). Mathematics for Economists, Viva Norton Student Edition. New York.

Wagner, J. (1997). Firm Size and Job Quality: A Survey of the Evidence from Germany. Small Business Economics, 9(5), 411-425. doi: http://www.jstor.org/stable/40228597

Waldorf, H. W. (1973). Quality of Labor in Manufacturing. The Review of Economics and Statistics, 55(3), 284-290.

Wang, S., Meng, Q., \& Liu, Z. (2013). On the weighting of the mean-absolute-deviation cost minimization model. Journal of the Operational Research Society, 64(4), 622-628. 